\title{
Efficacy of Repair for ACL Injury: A Meta-analysis of Randomized Controlled Trials
}

\section{() (1) $(8)$}

\author{
Author \\ Zhuoyang Li
}

\begin{abstract}
Affiliation
Zhejiang University School of Medicine First Affiliated

Hospital, Orthopedics, Hangzhou, China
\end{abstract}

Key words

anterior cruciate ligament, primary repair, arthroscopy, reconstruction, meta-analysis, randomized controlled trial

accepted 26.01.2022

published online $\quad 03.06 .2022$

Bibliography

Int J Sports Med 2022; 43: 1071-1083

DOI 10.1055/a-1755-4925

ISSN $0172-4622$

(c) 2022. The Author(s).

This is an open access article published by Thieme under the terms of the Creative Commons Attribution-NonDerivative-NonCommercial-License, permitting copying and reproduction so long as the original work is given appropriate credit. Contents may not be used for commercial purposes, or adapted, remixed, transformed or built upon. (https://creativecommons. org/licenses/by-nc-nd/4.0/)

Georg Thieme Verlag KG, Rüdigerstraße 14,

70469 Stuttgart, Germany

Correspondence

Dr. Zhuoyang Li

Zhejiang University School of Medicine First Affiliated

Hospital

Orthopedics

Qingchun road 79, hangzhou, China

310003 Hangzhou

China

Tel.: + 139/681/51 204, Fax: + 872/368/48

1317027@zju.edu.cn

\begin{abstract}
We aim to compare the curative effect of primary repair for anterior cruciate ligament $(\mathrm{ACL})$ injury with reconstruction and provide the reliable evidence for its clinical application. The literatures were searched in PubMed, EMBASE, Springer, and other medical literature databases published between January 1970 and June 2021. Basic characteristics, surgery technique, clinical outcome scores and physical examination results were recorded and evaluated. Seven randomized controlled trials (RCT) were eligible for inclusion. The results showed that there were no statistically significant differences between arthroscopic $A C L$ repair and $A C L$ reconstruction for Tegner, Lysholm, Lachman, KT-1000, range of motion (ROM), functional outcomes and reoperation rate $(P>0.05)$, even the result of IKDC scores showed that arthroscopic repair was better than reconstruction $(P=0.04)$. However, through the subgroup analysis, it was found that the short-term follow-up results of arthroscopic $A C L$ repair were indeed better than those of open $A C L$ repair. Therefore, we can assume that the arthroscopic $A C L$ repair technique is an optional and promising surgical method to treat $A C L$ injury.
\end{abstract}

\section{Introduction}

Anterior cruciate ligament $(A C L)$ injury is one of the most common types of knee joint injury. According to statistics, 85 out of every 100,000 people aged 16-39 suffer from ACL injury [1]. Mayo et al. successfully performed one-stage open ACL repair surgery for the first time since 1895 and reported the good results of the surgery [2]. By the 1970s, after a long-term follow-up study of ACL repair
Feagin and other scholars found that although the early follow-up results were satisfactory, the long-term curative effect was not good enough, and the rate of patients receiving reoperation within 5 years was also relatively high [3-6]. Therefore, primary ACL repair surgery was no longer popular.

After that, ACLR gradually replaced ACL repair as the mainstream surgical method for the treatment of ACL injury. However, 
many studies have pointed out that ACLR surgery has some deficiencies such as postoperative ligament proprioception loss, tendon donor site complications, autologous or allogeneic graft infection, etc., and the postoperative functional recovery still needs to be improved $[7,8]$. This may be related to the fact that the reconstructed ligament cannot effectively restore the normal anatomical structure and physiological function of $\operatorname{ACL}[9,10]$. Therefore, more and more scholars are focusing on preserving the biology of $A C L$ to improve the surgical results. With the wide application of arthroscopy, the use of new surgical instruments and implants, and the deepening understanding of the biological knowledge of ACL, people have generated new interest in $A C L$ repair [11-14]. At the same time, compared with $A C L R, A C L$ repair has less damage, no donor site complications and can restore active function earlier $[15,16]$.

In recent years, we have reason to think that $A C L$ repair should be re-evaluated with the rapid development of some arthroscopic techniques and the adjustment of postoperative rehabilitation strategies. Considering that some results in historical literature were not satisfactory [17-20], we will re-evaluate the safety and effectiveness of one-stage $A C L$ repair technology by meta-analysis. Although some review studies have been reported in recent years [21-23], there has been no high-quality systematic review related to randomized controlled trial (RCT). The objective of this study is to evaluate all clinical RCT research of primary $A C L$ repair (open and arthroscopic) in recent decades, and compare the results between $\mathrm{ACL}$ repair and reconstruction, so as to provide more reliable evidence for clinical treatment.

\section{Materials and Methods}

\section{Retrieval strategies}

We searched PubMed, EMBASE, Springer, Ovid, the Cochrane Library, and other medical literature databases for the literature related to the comparison of clinical outcomes between one-stage $A C L$ repair and ACLR in all adults published between January 1970 and June 2021. Keywords: anterior cruciate ligament, injury, repair, reconstruction. The type of studies included was RCT only. Also, review articles on this topic were reviewed to retrieve relevant studies that might have been missed.

\section{Inclusion criteria}

Inclusion criteria included (1) diagnosis of ACL injury; (2) RCT; (3) intervention: experimental group with $\mathrm{ACL}$ repair techniques; control group with conventional ACLR. (4) The observation indexes included: prognostic indexes (Tegner, Lysholm, IKDC scores), physical examination results (Lachman test, range of motion, tibial anterior displacement), reoperation rate, and functional outcomes.

\section{Exclusion criteria}

Exclusion criteria included the following: (1) non-RCT studies; (2) no relevant interventions were included in the above types of literature; (2) follow-up less than 12 months; (3) cadaveric studies, biomechanical studies, and in vitro or animal studies; and (4) duplicate published studies were excluded, and abstracts, lectures, and reviews were also excluded.

\section{Data extraction and quality evaluation}

We extracted relevant data by retrieving information and summarized them into tables and forest plots. The quality of the included studies was evaluated using Revman software. The parameters included sequence generation (selection bias), allocation hiding (selection bias), blindness (performance bias), incomplete result data (detection bias), selective result reporting (reporting bias), and other issues. Each parameter could be classified as low risk, high risk, or unclear.

\section{Statistical analysis}

Statistical analyses were performed using Revman manager 5.3 software (Cochrane Collaboration, NordicCochrane Centre, Copenhagen, Denmark). Continuous variables were analyzed using weighted mean differences, and categorical variables were assessed using relative risk or absolute risk differences. $p<0.05$ was considered statistically significant. Heterogeneity analysis was tested by Q-statistic $(P<0.1)$, and I2-statistic $\left(I^{2}>50 \%\right)$. When there was no statistically significant heterogeneity, a fixed-effects model was used; conversely, a random-effects model was used. In addition, we performed subgroup analyses depending on the intervention.

\section{Results}

\section{Study selection}

The literature search identified 86 papers that met the study objectives, and we selected 7 RCTs that met the inclusion criteria [17$20,24-26]$, with a total of 745 patients, of which a total of 61 patients were lost to follow-up, with the rate of $8.2 \%$. The literature search process is shown in - Fig. $\mathbf{1}$, and the basic characteristics of these studies are shown in $>$ Table 1.

\section{Surgical techniques}

$A C L$ repair technique

There were 3 papers on open ACL repair [24-26], including 109 patients. The surgical techniques consisted of 2 main categories: primary repair without augmentation or with ligament augmentation device (LAD). The surgical procedures were described in detail in previous literature $[24,25,27]$. primary repair technique of the 3 studies was performed according to the method reported by Palmer [28].

The arthroscopic ACL repair technique had been reported in 4 papers [17-20], including 160 patients. These patients were treated with the DIS technique and BEAR technique, respectively. The DIS procedure was performed according to the technique described by Kösters [29] and Eggli [30]. A total of 96 patients were included. The BEAR procedure was performed according to the technique described by Murray [31] and included a total of 64 patients.

\section{ACLR technique}

ACLR interventions were used in all seven publications, including a total of 415 patients. The ACLR grafts used included: 1. Bone-patellar tendon-bone graft; 2 . autologous semitendinosus-gracilis tendon graft. 
Quality assessment

We performed a quality assessment of the seven included RCTs using the Cochrane Risk of Bias Assessment Tool. The entire assessment was performed by two reviewers separately, and any disagreements were resolved by a third reviewer. As shown in > Fig. 2 , the quality of the included studies was high. The funnel plot shows no visual evidence of publication bias.

\section{Meta-analysis results}

The seven included studies used different knee function scoring systems. We divided the results of the studies into two groups, the experimental $A C L$ repair group and the control ACLR group, for comparison. It needs to be mentioned that we combined the data from the $A C L$ repair with or without LAD group at the same time for the meta-analysis, and did the independent subgroup analysis

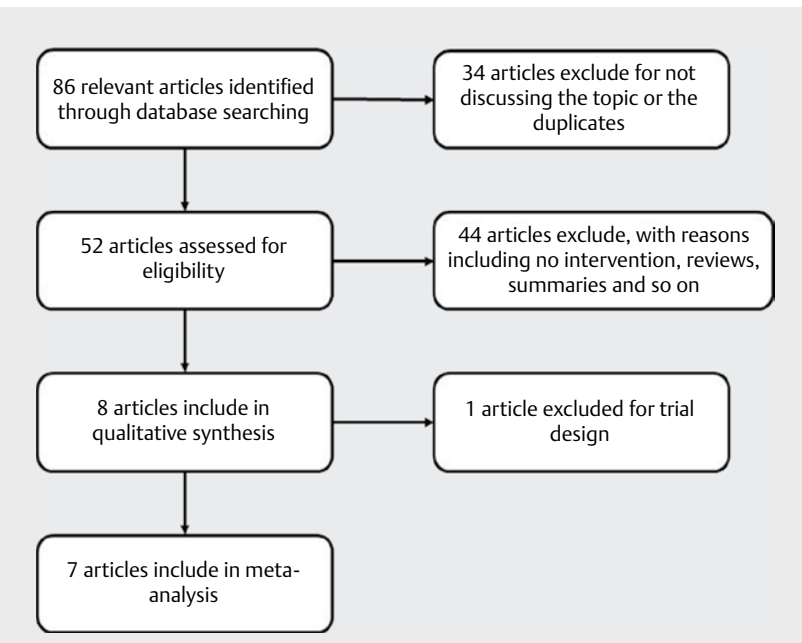

Fig. 1 Search strategy flow diagram. respectively, in order to evaluate the results of the meta-analysis in a comprehensive manner.

\section{Knee clinical scores}

\section{Tegner score and subgroup analysis}

We included five studies comparing the results of postoperative Tegner scores in the two groups. The Tegner scores in the two groups were 3-6.8 and 4-7.1, respectively. The difference between the two groups was statistically significant, and overall, the postoperative Tegner score was higher in the ACLR group than in the $A C L$ repair group $(S M D=-0.55,95 \% C l-0.88$ to $-0.21, p=0.001$, $\left.\mathrm{I}^{2}=0 \%\right)$ ( Fig. 3a).

We also performed subgroup analysis by intervention and showed that there was no statistically significant difference in Tegner scores between arthroscopic $A C L$ repair and $A C L R$ $\left(\mathrm{SMD}=-0.22,95 \% \mathrm{Cl}-0.82\right.$ to $\left.0.39, \mathrm{P}=0.49, \mathrm{I}^{2}=0 \%\right)$. In contrast, the difference between open $A C L$ repair and $A C L R$ was statistically significant $\left(\mathrm{SMD}=-0.69,95 \% \mathrm{Cl}-1.09\right.$ to $-0.29, \mathrm{P}=0.0007, \mathrm{I}^{2}=0 \%$ ). Overall, the postoperative Tegner score was higher in the ACLR group than in the open $A C L$ repair group ( $\mathbf{F i g}$. $3 a$ ).

\section{Lysholm score and subgroup analysis}

There were five included studies comparing the results of postoperative Lysholm scores between the two groups. The differences between the two groups were statistically significant, with higher postoperative Lysholm score in the ACLR group than in the $\mathrm{ACL}$ repair group overall $(S M D=-3.26,95 \% \mathrm{Cl}-5.98$ to $-0.54, p=0.02$, $12=67 \%$ ) ( $>$ Fig. $3 \mathbf{b})$.

We also performed subgroup analysis by intervention and showed that there was no statistically significant difference in Lysholm scores between arthroscopic $A C L$ repair and $A C L R(S M D=2.35,95 \% C l-1.97$ to 6.66, $P=0.29,12=0 \%$ ). In contrast, the difference between open $A C L$ repair and ACLR was statistically significant, with higher postop-

- Table 1 Basic characteristics of included studies

\begin{tabular}{|c|c|c|c|c|c|c|c|}
\hline \multirow[t]{2}{*}{ Included Studies } & \multirow{2}{*}{$\begin{array}{l}\mathrm{N} \\
\text { (M\%/F\%) }\end{array}$} & \multirow{2}{*}{$\begin{array}{l}\text { Age }(y) \\
\text { Mean } \pm \text { SD } \\
\text { (Min-Max) }\end{array}$} & \multirow[t]{2}{*}{ Repair technique } & \multirow{2}{*}{$\begin{array}{l}\text { Reconstruction } \\
\text { technique }\end{array}$} & \multirow{2}{*}{$\begin{array}{l}\begin{array}{l}\text { Injury to } \\
\text { operation }\end{array} \\
\text { Interval } \\
\text { (d) }\end{array}$} & \multicolumn{2}{|l|}{$\mathbf{F} / \mathbf{U}$} \\
\hline & & & & & & $\begin{array}{l}\text { Dura- } \\
\text { tion (y) }\end{array}$ & $\begin{array}{l}\text { n (\% Lost } \\
\text { F/U) }\end{array}$ \\
\hline Engebretsen et al. (1990) [24] & $150(54 \% / 46 \%)$ & $28.7(16-50)$ & $\begin{array}{l}\text { Primary repair with } \\
\text { or without LAD }\end{array}$ & ВРТВ & 10 & 2 & $3(2 \%)$ \\
\hline Grontvedt et al. (1996) [25] & 150 & $29(16-50)$ & $\begin{array}{l}\text { Primary repair with } \\
\text { or without LAD }\end{array}$ & ВРТВ & 10 & 5 & $9(6 \%)$ \\
\hline Sporsheim et al. (2019) [26] & 150 & $29(16-54)$ & $\begin{array}{l}\text { Primary repair with } \\
\text { or without LAD }\end{array}$ & ВРТВ & NA & 30 & $37(24.7 \%)$ \\
\hline Schliemann et al. (2018) [17] & $62(62 \% / 38 \%)$ & $28.7 \pm 11.4$ & DIS & $\begin{array}{l}\text { ACLR (semitendi- } \\
\text { nosus autograft) }\end{array}$ & 21 & 1 & $2(3.2 \%)$ \\
\hline Hoogeslag et al. (2019) [20] & $48(77 \% / 23 \%)$ & $21.5 \pm 2.7$ & DIS & $\begin{array}{l}\text { ACLR (semitendi- } \\
\text { nosus autograft) }\end{array}$ & 21 & 2 & $4(8.3 \%)$ \\
\hline Murray et al. (2020) [18] & $100(44 \% / 56 \%)$ & $17 \pm 1.5$ & BEAR & $\begin{array}{l}\text { ACLR (semitendi- } \\
\text { nosus autograft) }\end{array}$ & 45 & 2 & $4(4 \%)$ \\
\hline Sters et al. (2020) [19] & $85(66 \% / 34 \%)$ & $28.2 \pm 11(18-46)$ & DIS & $\begin{array}{l}\text { ACLR (semitendi- } \\
\text { nosus autograft) }\end{array}$ & NA & 1 & $2(2.3 \%)$ \\
\hline
\end{tabular}


a
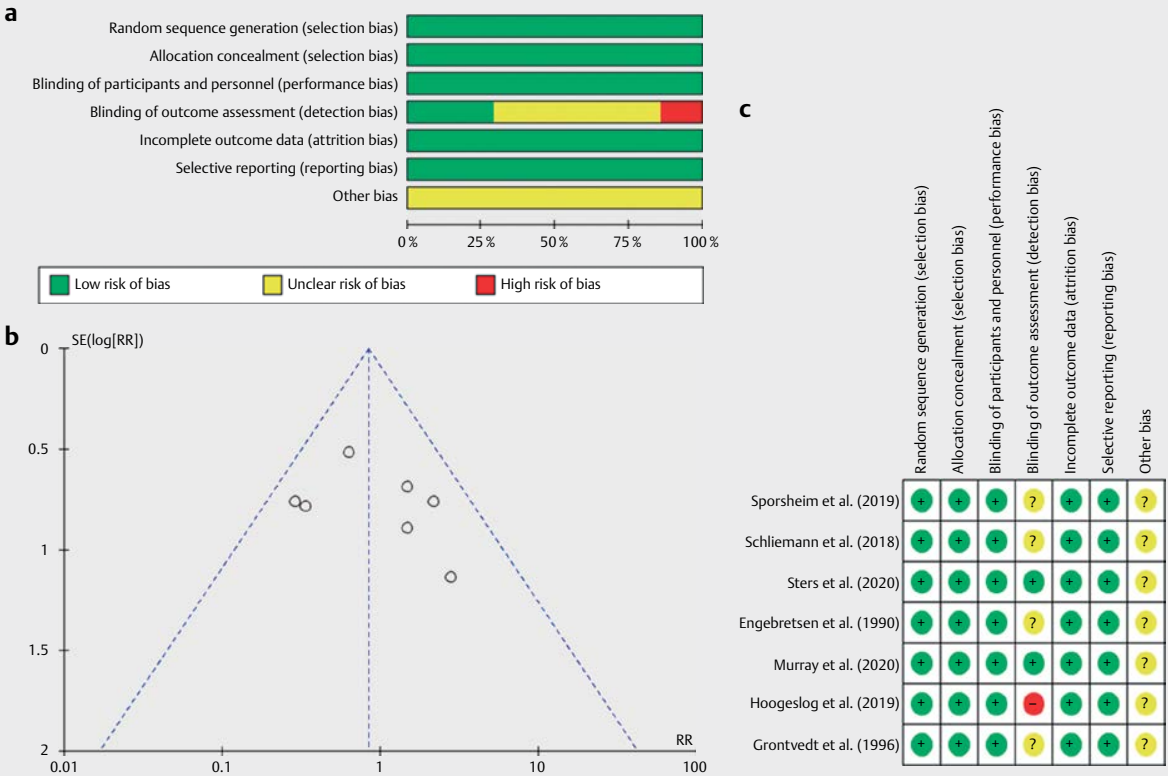

Fig. 2 a Risk of bias graph exhibiting the review of the authors' judgments about each risk of bias item presented as percentages across all included studies. $\mathbf{b}$ Risk of bias summary revealing the review of the authors' judgments about each risk of bias item for included RCTs. Minus sign represents the risk of bias present, plus sign indicates the risk of bias absent, and question mark equals the risk of bias uncertain. $\mathbf{c}$ The funnel plots of the included studies. RR, relative risks; SE, standard error.

erative Lysholm score in the ACLR group than in the open $A C L$ repair group overall $(\mathrm{SMD}=-4.80,95 \% \mathrm{Cl}-6.24$ to $-3.36, \mathrm{P}<0.05, \mathrm{I} 2=0 \%)$. ( Fig. 3b).

\section{IKDC scores}

There were four included studies of arthroscopic ACL repair comparing the results of postoperative IKDC scores between the two groups. The IKDC scores in the two groups were 85.7-95.4 and 84.8-94.3, respectively. The difference between the two groups was statistically significant, and the postoperative IKDC scores were higher in the arthroscopic $A C L$ repair group than in the ACLR group overall $(\mathrm{SMD}=2.12,95 \% \mathrm{Cl} 0.14$ to $4.10, \mathrm{p}=0.04 .12=0 \%$ ( $\mathbf{F i g} .4 a)$.

\section{Physical examination results}

\section{Lachman test}

There were five included studies comparing the postoperative Lachman test results $(2+/ 3+)$ between the two groups. There was no statistically significant difference in the postoperative Lachman test results between the two groups, with Lachman $2+13+$ rates of 22.3 and $7.8 \%$, respectively $(S M D=0.09,95 \% \mathrm{Cl}-0.06$ to $0.24, \mathrm{P}=0.24$, $12=90 \%$ ) ( Fig. $\mathbf{5}$ ).

We also performed subgroup analysis by intervention and showed that there was no statistically significant difference in Lachman test results between arthroscopic $A C L$ repair and $A C L R(S M D=-0.02,95 \%$ $\mathrm{Cl}-0.08$ to $0.04, \mathrm{P}=0.48, \mathrm{I} 2=0 \%$ ). In contrast, the difference between open $A C L$ repair and ACLR was statistically significant $(\mathrm{SMD}=0.18,95 \% \mathrm{Cl} 0.01$ to $0.34, \mathrm{P}=0.04, \mathrm{I}=77 \%$ ). ( Fig. $3 a$ ). Overall, the rate of postoperative Lachman test $2+13+$ was lower in the ACLR group than in the open ACL repair group, which were 9.7 and $30.7 \%$, respectively.

\section{Anterior-posterior knee stability test (KT-1000)}

All three included open $A C L$ repair studies compared the results of the postoperative KT-1000 test ( $>=3 \mathrm{~mm}$ ) between the two groups. The results showed no statistically significant difference between the two groups ( $S M D=1.58,95 \% \mathrm{Cl} 0.54$ to $4.62, \mathrm{P}=0.40$, $12=90 \%$ ( $($ Fig. 4 b) .

\section{Knee flexion mobility}

There were four included studies comparing the results of postoperative knee flexion mobility changes between the two groups. The results showed no statistically significant difference between the two groups, with 8.2 and $6.9 \%$ of knee flexion limitations greater than $10^{\circ}$, respectively. ( $\mathrm{SMD}=1.22,95 \% \mathrm{Cl} 0.62$ to $2.42, \mathrm{P}=0.56$, $12=0 \%$ ) ( Fig. 6a).

\section{Knee extension mobility}

There were four included studies comparing the results of postoperative knee extension mobility changes between the two groups. The results showed no statistically significant difference between the two groups, with 9.6 and $13.2 \%$ of knee extension limitations greater than $5^{\circ}$, respectively. $(\mathrm{SMD}=0.76,95 \% \mathrm{Cl} 0.45$ to 1.30 , $P=0.32,12=3 \%)$ ( $>$ Fig. 6 b).

\section{knee functional outcomes}

There were 2 studies assessing the strength changes of muscles surrounding the knee joint in patients after surgery, such as the 


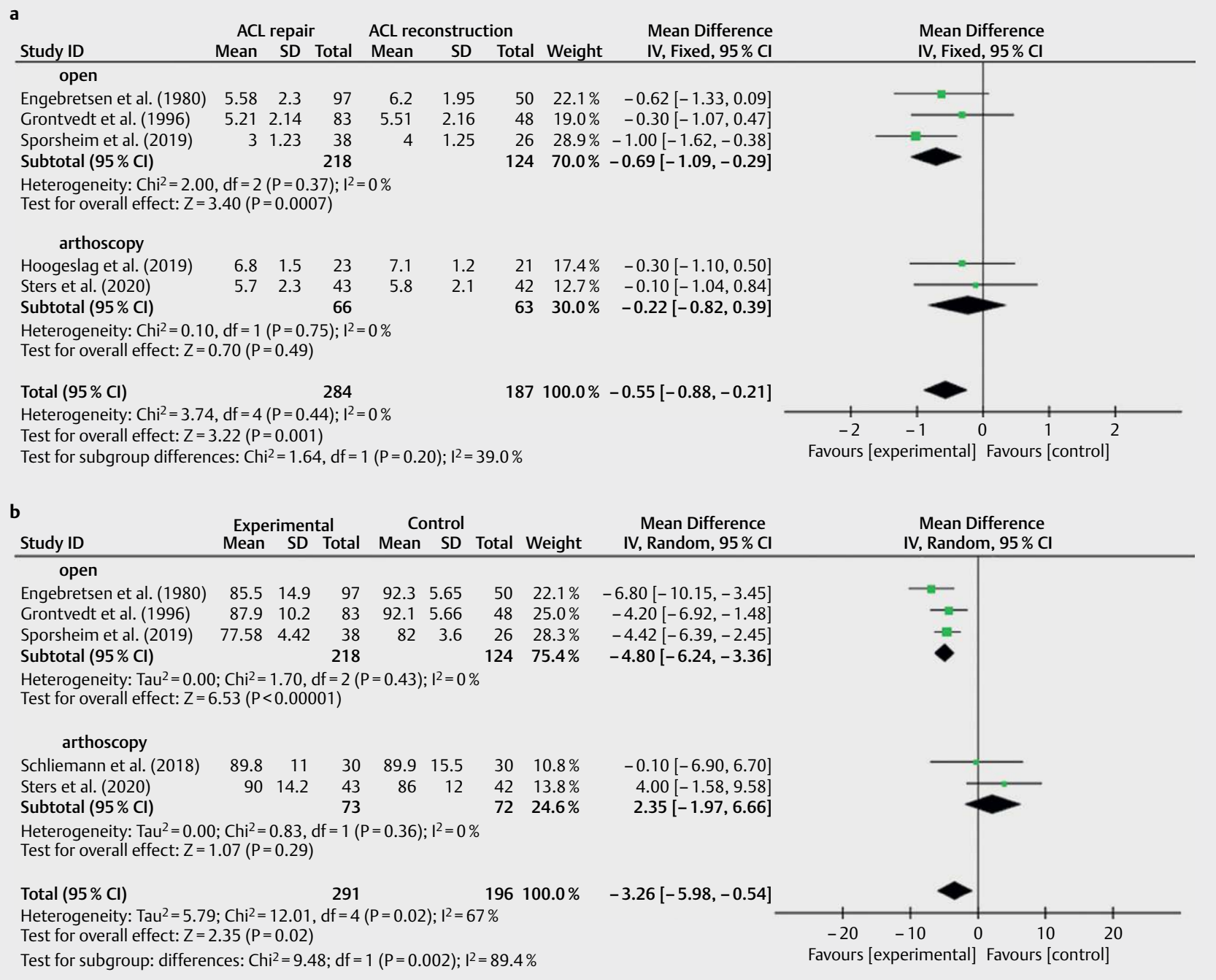

- Fig. 3 a Difference in the Tegner score and the subgroup analysis; b Difference in the Lysholm score and the subgroup analysis. Cl, confidence interval; IV, inverse variance; SD, standard deviation. The solid squares indicate the mean difference and are proportional to the weights used in the meta-analysis. The solid vertical line indicates no effect. The horizontal lines represent the $95 \% \mathrm{Cl}$. The diamond indicates the weighted mean difference, and the lateral tips of the diamond indicate the associated $95 \% \mathrm{Cl}$.

hamstrings, quadriceps and hip abductor muscle groups. The results were as follows: There was no statistically significant difference in the comparison of knee muscle functional outcomes between the two groups. (SMD $=0.27,95 \% \mathrm{Cl}-2.69$ to $3.23, \mathrm{P}=0.86$, $12=92 \%)(\triangleright$ Fig. 7).

\section{Reoperation rate}

There were five included studies comparing the reoperation rates during postoperative follow-up between the two groups. The results showed that the difference between the two groups in postoperative reoperation rates was not statistically significant, with rates of 15.5 and $9.8 \%$, respectively (SMD $=1.61,95 \% \mathrm{Cl} 0.99$ to 2.61, $\mathrm{P}=0.06,12=31 \%$ ) (> Fig. 8).

Our subgroup analysis by intervention showed that there was no statistically significant difference in the reoperation rates between arthroscopic $A C L$ repair and $A C L R(S M D=1.02,95 \% \mathrm{Cl} 0.48$ to 2.18, $\mathrm{P}=0.95, \mathrm{I} 2=0 \%$ ). In contrast, the difference between open $\mathrm{ACL}$ repair and ACLR was statistically significant, and the rate of postoperative reoperation was lower in the ACLR group than in the open $A C L$ repair group overall, which were 7.4 and $15.4 \%$, respectively $(\mathrm{SMD}=2.05,95 \% \mathrm{Cl} 1.08$ to $3.88, \mathrm{P}=0.03, \mathrm{I} 2=48 \%$ ( $($ Fig. 8 ).

\section{Subgroup analysis of LAD}

Finally, we performed subgroup analysis on whether to use LAD for $A C L$ repair or not. And the statistical analysis was performed separately according to the type of data, and the results were summarized in ( $\vee$ Fig. 9, 10).

The results showed that for $A C L$ repair with or without LAD assistance, there was no statistically significant difference between the two groups for comparison of either subjective knee scores or 


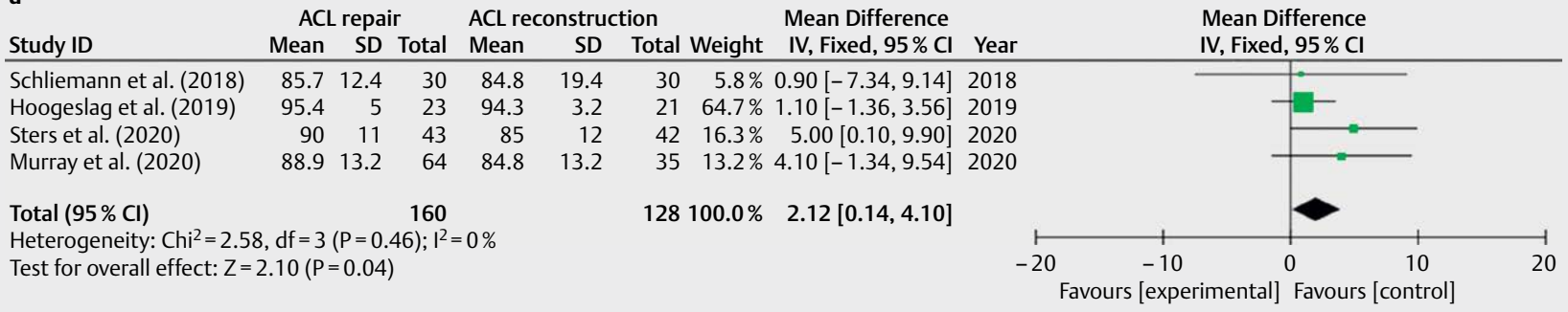

b

\section{Study ID}

Engebretsen et al. (1980)

Grontvedt et al. (1996)

ACL repair $\quad A C L$ reconstruction

Risk Ratio

Events Total Events Total Weight M-H, Random, $95 \% \mathrm{Cl}$

$2.68[1.49,4.81]$

$\begin{array}{lll}50 & 33.3 \% & 2.68[1.49,4.81] \\ 48 & 33.3 \% & 2.72[1.52,4.87]\end{array}$

Sporsheim et al. (2019)

$\begin{array}{ll}52 & 97 \\ 47 & 83\end{array}$

10

$\begin{array}{ll}48 & 33.3 \% \\ 26 & 33.4 \%\end{array}$

$0.55[0.31,0.97]$

Total $(95 \% \mathrm{Cl})$

$\begin{array}{ll}47 & 83 \\ 12 & 38\end{array}$

15

$124100.0 \%$

Total events

218

111

35

Heterogeneity: Tau $^{2}=0.81 ; \mathrm{Chi}^{2}=20.45, \mathrm{df}=2(\mathrm{P}<0.0001) ; \mathrm{I}^{2}=90 \%$

Test for overall effect: $\mathrm{Z}=0.84(\mathrm{P}=0.40)$

$1.58[0.54,4.62]$

$\mathrm{M}-\mathrm{H}$, Random, $95 \% \mathrm{Cl}$

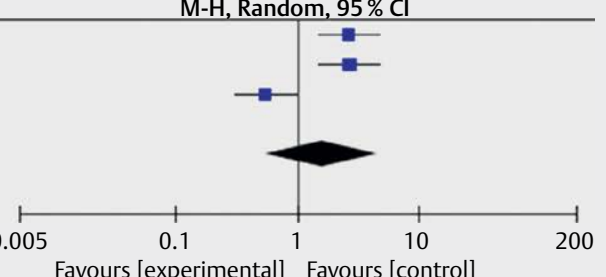

Fig. 4 a Difference in the IKDC score; b Difference in the incidence of KT-1000 ( $\geq 3 \mathrm{~mm}$ ). Cl, confidence interval; IV, inverse variance; M-H, MantelHaenszel. The solid squares indicate the mean difference and are proportional to the weights used in the meta-analysis. The solid vertical line indicates no effect. The horizontal lines represent the $95 \% \mathrm{Cl}$. The diamond indicates the weighted mean difference, and the lateral tips of the diamond indicate the associated $95 \% \mathrm{Cl}$.

\begin{tabular}{|c|c|c|c|c|c|}
\hline & ACL repair & $\mathrm{ACL}$ reconstruction & & Risk Difference & Risk Difference \\
\hline Study ID & Events Total & Events Total & Weight & M-H, Random, $95 \%$ Cl & M-H, Random, 95\% Cl \\
\hline
\end{tabular}

\begin{tabular}{lrrrrrr} 
& Events & Total & Events & Total & Weight & M-H, Random, 95\% Cl \\
\hline$\quad$ open & & & & & & \\
Engebretsen et al. (1980) & 33 & 97 & 4 & 50 & $19.9 \%$ & $0.26[0.14,0.38]$ \\
Grontvedt et al. (1996) & 30 & 83 & 5 & 48 & $19.3 \%$ & $0.26[0.12,0.39]$ \\
Sporsheim et al. (2019) & 4 & 38 & 3 & 26 & $18.3 \%$ & $-0.01[-0.17,0.15]$ \\
Subtotal (95\% Cl) & & 218 & & 124 & $57.5 \%$ & $0.18[0.01,0.34]$ \\
Total events & 67 & & 12 & & &
\end{tabular}

Heterogeneity: $\operatorname{Tau}^{2}=0.02 ; \mathrm{Chi}^{2}=8.63, \mathrm{df}=2(\mathrm{P}=0.01) ; \mathrm{I}^{2}=77 \%$

Test for overall effect: $Z=2.09(P=0.04)$

arthoscopy

$\begin{array}{llllllr}\text { Hoogeslag et al. (2019) } & 0 & 23 & 0 & 21 & 21.2 \% & 0.00[-0.08,0.08] \\ \text { Murray et al. (2020) } & 1 & 64 & 2 & 35 & 21.3 \% & -0.04[-0.12,0.04] \\ \text { Subotal }(95 \% \mathrm{Cl}) & & 87 & & 56 & 42.5 \% & -0.02[-0.08,0.04] \\ \text { Total events } & 1 & & 2 & & & \end{array}$

1

2

Heterogeneity: $\operatorname{Tau}^{2}=0.00 ; \mathrm{Chi}^{2}=0.52, \mathrm{df}=1(\mathrm{P}=0.47) ; \mathrm{I}^{2}=0 \%$

Test for overall effect: $Z=0.70(P=0.48)$

Total $(95 \% \mathrm{Cl})$

Total events

305

Heterogeneity: $\mathrm{Tau}^{2}=0.03 ; \mathrm{Chi}^{2}=38.23, \mathrm{df}=4(\mathrm{P}<0.00001) ; \mathrm{I}^{2}=90 \%$

Test for overall effect: $Z=1.17(P=0.24)$

Test for subgroup differences: $\mathrm{Chi}^{2}=4.87, \mathrm{df}=1(\mathrm{P}=0.03) ; \mathrm{I}^{2}=79.5 \%$

$180100.0 \% \quad 0.09[-0.06,0.24]$ M-H, Random, $95 \%$ C

Fig. 5 Difference in the incidence of Lachman test $(2+/ 3+)$ and the subgroup analysis; $\mathrm{Cl}$, confidence interval; IV, inverse variance; M-H, MantelHaenszel. The solid squares indicate the mean difference and are proportional to the weights used in the meta-analysis. The solid vertical line indicates no effect. The horizontal lines represent the $95 \% \mathrm{Cl}$. The diamond indicates the weighted mean difference, and the lateral tips of the diamond indicate the associated $95 \% \mathrm{Cl}$.

objective examination findings. (SMD $=-0.18,95 \% \mathrm{Cl}-0.67$ to 0.31 , $\mathrm{P}=0.48, \mathrm{I} 2=30 \%$; SMD $=0.06,95 \% \mathrm{Cl}-0.00$ to $0.12, \mathrm{P}=0.06$, $12=63 \%)$.

Moreover, we performed subgroup analyses of each scoring system and found that there were no statistically significant differences in the results of each test except for the Lysholm score and KT-1000 test $(P=0.89,0.32,0.50,0.95,0.68)$, which showed better results in the $A C L+L A D$ group than in the $A C L$ repair alone $(P=0.01$ and $0.003)$. 


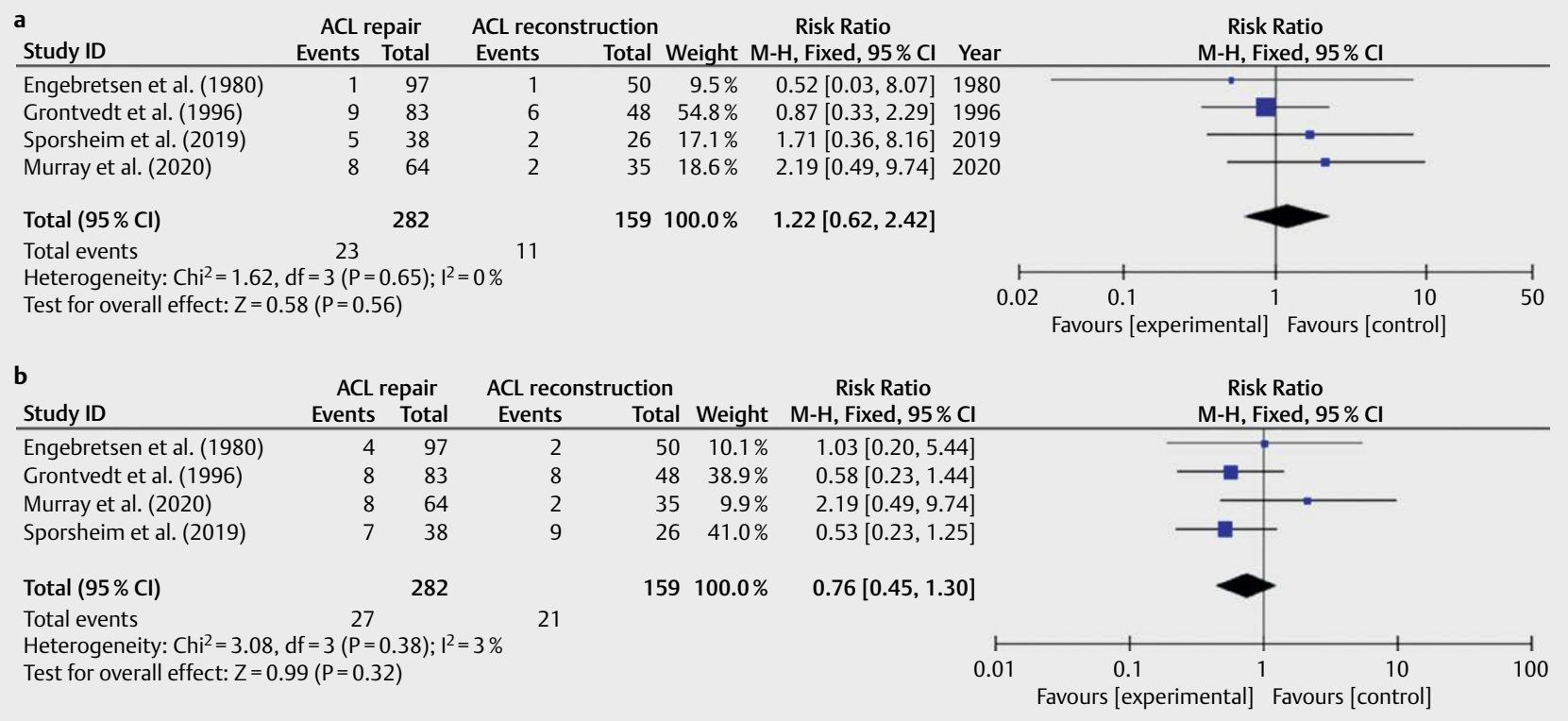

- Fig. 6 a Difference in the incidence of flexion limitation $\left(\geq 10^{\circ}\right)$; b Difference in the incidence of extension limitation $\left(\geq 5^{\circ}\right)$. $\mathrm{Cl}$, confidence interval; IV, inverse variance; M-H, Mantel-Haenszel. The solid squares indicate the mean difference and are proportional to the weights used in the metaanalysis. The solid vertical line indicates no effect. The horizontal lines represent the $95 \% \mathrm{Cl}$. The diamond indicates the weighted mean difference, and the lateral tips of the diamond indicate the associated $95 \% \mathrm{Cl}$.

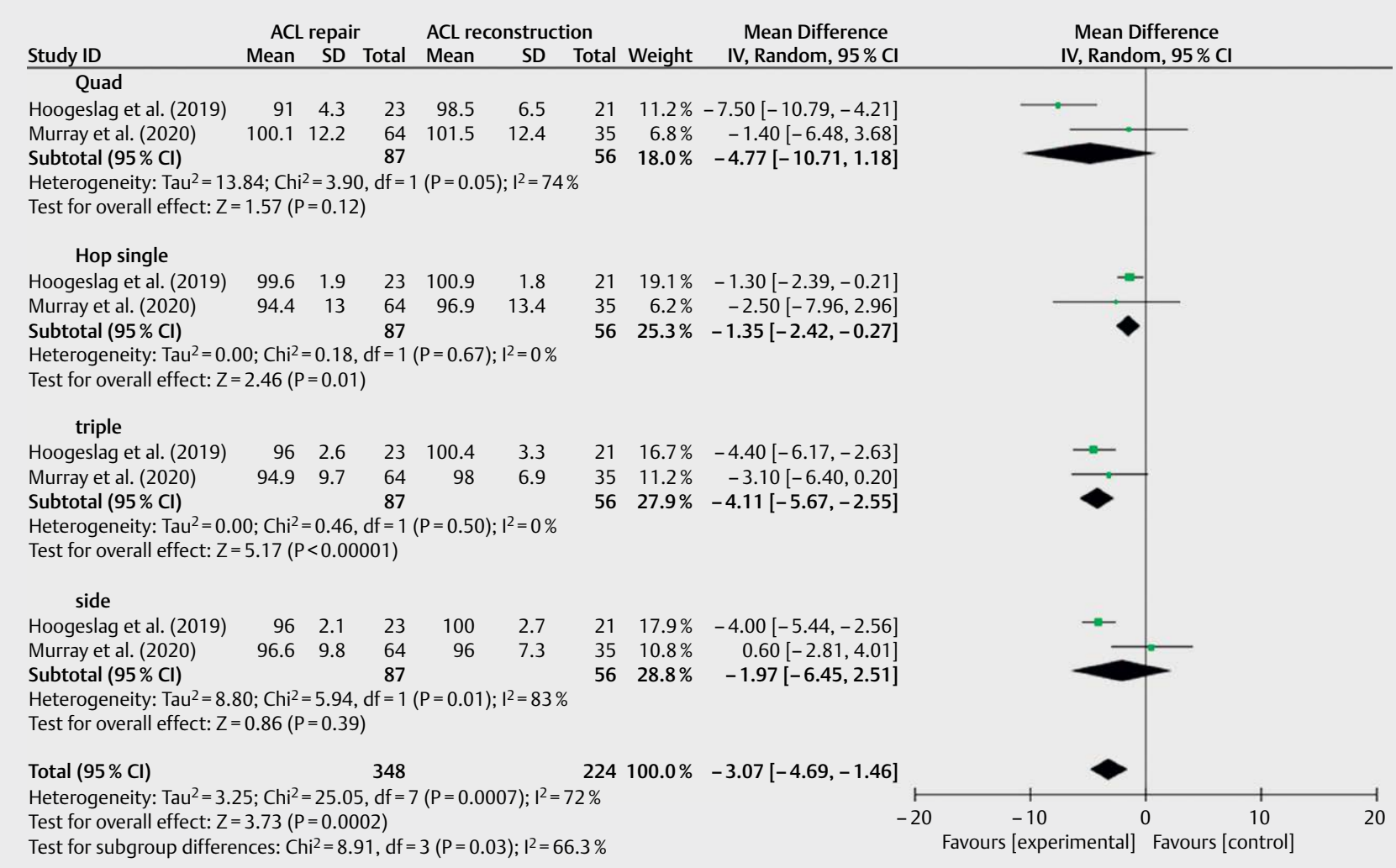

- Fig. 7 Difference in the functional outcomes of muscle strength and the subgroup analysis. CI, confidence interval; IV, inverse variance; SD, standard deviation. The solid squares indicate the mean difference and are proportional to the weights used in the meta-analysis. The solid vertical line indicates no effect. The horizontal lines represent the $95 \% \mathrm{Cl}$. The diamond indicates the weighted mean difference, and the lateral tips of the diamond indicate the associated $95 \% \mathrm{Cl}$. 


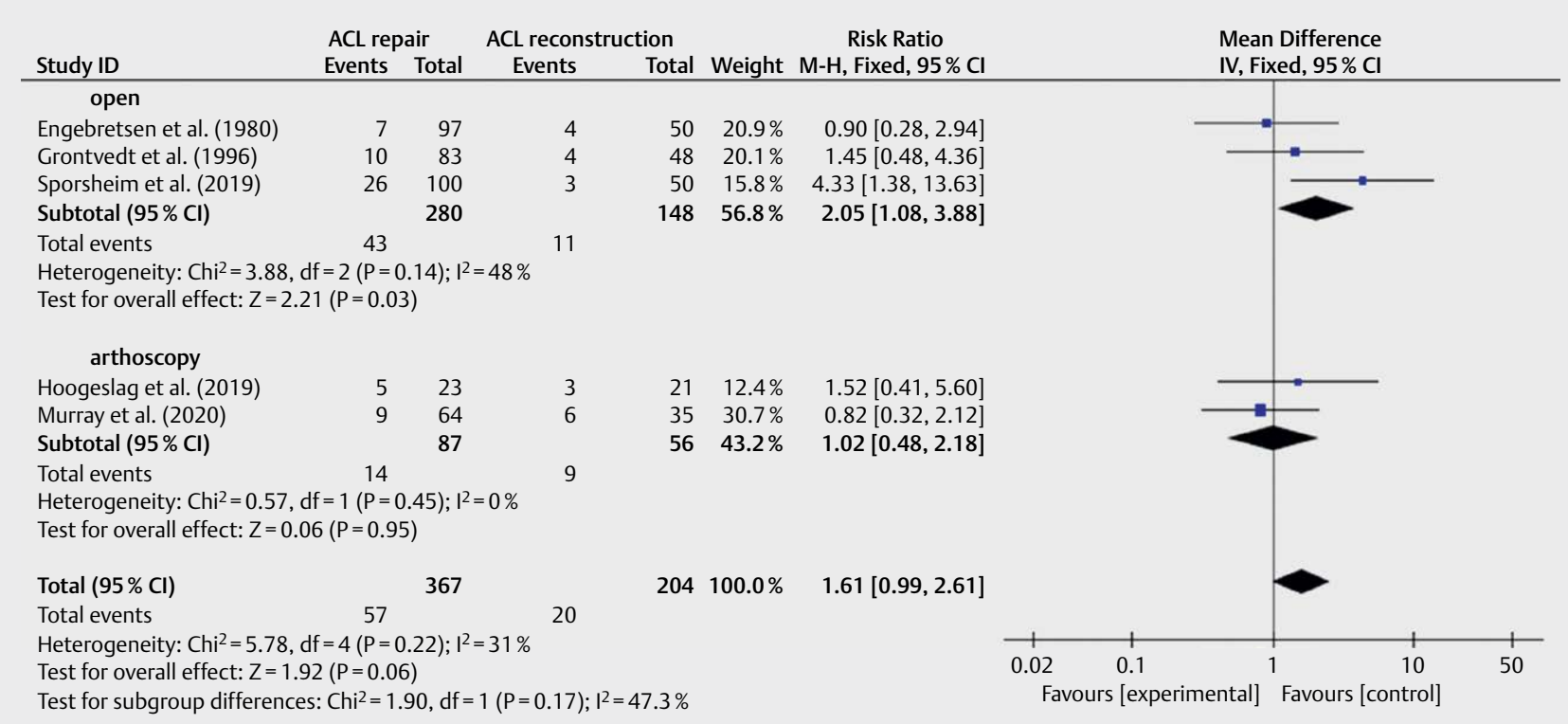

- Fig. 8 Difference in the incidence of reoperation and the subgroup analysis. $\mathrm{Cl}$, confidence interval; $\mathrm{M}-\mathrm{H}$, Mantel-Haenszel. The solid squares indicate the mean difference and are proportional to the weights used in the meta-analysis. The solid vertical line indicates no effect. The horizontal lines represent the $95 \% \mathrm{Cl}$. The diamond indicates the weighted mean difference, and the lateral tips of the diamond indicate the associated $95 \% \mathrm{Cl}$.

\begin{tabular}{|c|c|c|c|c|c|c|c|c|c|c|c|c|}
\hline \multirow[b]{2}{*}{ Study ID } & \multicolumn{3}{|c|}{ Experiment } & \multicolumn{3}{|c|}{ Control } & \multicolumn{3}{|c|}{ Mean Difference } & & \multirow{2}{*}{\multicolumn{2}{|c|}{$\begin{array}{l}\text { Mean Difference } \\
\text { IV, Fixed, } 95 \% \mathrm{Cl}\end{array}$}} \\
\hline & Mean & SD & Total & Mean & SD & Total & Weight & IV, Fixed, $95 \% \mathrm{CI}$ & Year & & & \\
\hline \multicolumn{13}{|l|}{ Tegner } \\
\hline Engebretsen et al. (1980) & 5.56 & 2.28 & 50 & 5.6 & 2.34 & 47 & $28.5 \%$ & $-0.04[-0.96,0.88]$ & 1980 & & + & \\
\hline Grontvedt et al. (1996) & 5.17 & 2.2 & 41 & 5.25 & 2.1 & 42 & $28.1 \%$ & $-0.08[-1.01,0.85]$ & 1996 & & + & \\
\hline Sporsheim et al. (2019) & 3 & 1.25 & 18 & 3 & 1.25 & 20 & $38.1 \%$ & $0.00[-0.80,0.80]$ & 2019 & & + & \\
\hline Subtotal $(95 \% \mathrm{Cl})$ & & & 109 & & & 109 & $94.7 \%$ & $-0.04[-0.54,0.47]$ & & & 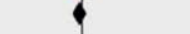 & \\
\hline \multicolumn{13}{|c|}{$\begin{array}{l}\text { Heterogeneity: } C^{2}{ }^{2}=0.02, d f=2(P=0.99) ; I^{2}=0 \% \\
\text { Test for overall effect: } Z=0.14(P=0.89)\end{array}$} \\
\hline \multicolumn{13}{|c|}{ Lysholm } \\
\hline Engebretsen et al. (1980) & 85.8 & 11.14 & 50 & 85.17 & 18.2 & 47 & $0.7 \%$ & $0.63[-5.42,6.68]$ & 1980 & & & \\
\hline Grontvedt et al. (1996) & 86 & 12.1 & 41 & 89.7 & 7.56 & 42 & $1.3 \%$ & $-3.70[-8.05,0.65]$ & 1996 & & & \\
\hline Sporsheim et al. (2019) & 76 & 4.1 & 18 & 79 & 4.3 & 20 & $3.4 \%$ & $-3.00[-5.67,-0.33]$ & 2019 & & & \\
\hline Subtotal $(95 \% \mathrm{Cl})$ & & & 109 & & & 109 & $5.3 \%$ & $-2.72[-4.85,-0.59]$ & & & & \\
\hline \multicolumn{13}{|c|}{$\begin{array}{l}\text { Heterogeneity: } \mathrm{Chi}^{2}=1.41, \mathrm{df}=2(P=0.49) ; \mathrm{I}^{2}=0 \% \\
\text { Test for overall effect: } Z=2.50(P=0.01)\end{array}$} \\
\hline Total $(95 \% \mathrm{Cl})$ & & & 218 & & & 218 & $100.0 \%$ & $-0.18[-0.67,0.31]$ & & & 4 & \\
\hline $\begin{array}{l}\text { Heterogeneity: } \text { Chi }^{2}=7.19 \\
\text { Test for overall effect: } Z=0\end{array}$ & $\begin{array}{l}9, \mathrm{df}=5 \\
0.71(\mathrm{P}\end{array}$ & $\begin{array}{l}5(P=0.2 \\
=0.48)\end{array}$ & $21) ; 1^{2}=$ & $=30 \%$ & & & & & $\begin{array}{r}\vdash \\
-20\end{array}$ & $\begin{array}{ll} & 1 \\
0 & -10\end{array}$ & 0 & 10 \\
\hline Test for subgroup differen & nces: Ch & $7 \mathrm{i}^{2}=5.7 \mathrm{f}$ & $6, d f=$ & $1(P=0$. & $.02) ; 1^{2}$ & $2=82.6$ & & & & Favours [expe & nental] Favours [c & ontrol] \\
\hline
\end{tabular}

- Fig. 9 Difference in the continuous variable results for ACL repair and the subgroup analysis. Cl, confidence interval; IV, inverse variance; SD, standard deviation; The solid squares indicate the mean difference and are proportional to the weights used in the meta-analysis. The solid vertical line indicates no effect. The horizontal lines represent the $95 \% \mathrm{Cl}$. The diamond indicates the weighted mean difference, and the lateral tips of the diamond indicate the associated $95 \% \mathrm{Cl}$.

\section{Postoperative rehabilitation protocols}

We summarized the protocols reported in the 7 included RCT studies regarding postoperative rehabilitation, as summarized in the table below. the 3 open $\mathrm{ACL}$ repair studies basically used the same rehabilitation protocol: long leg cast immobilization for 2 weeks, brace immobilization for 6 weeks, weight bearing after 8 weeks, muscle rehabilitation exercises after 12 weeks, and return to sports after 12 months. Compared to open $A C L$ repair, the rehabilitation protocols of the 4 arthroscopic ACL repair studies would be relatively more aggressive. There was no cast fixation, with adjustable brace use ranging from 4 days to 12 weeks, full weight bearing after 4 weeks, and a lower requirement for knee ROM limitation, with return to sports after 5-6 months ( $\triangleright$ Table 2 ). 


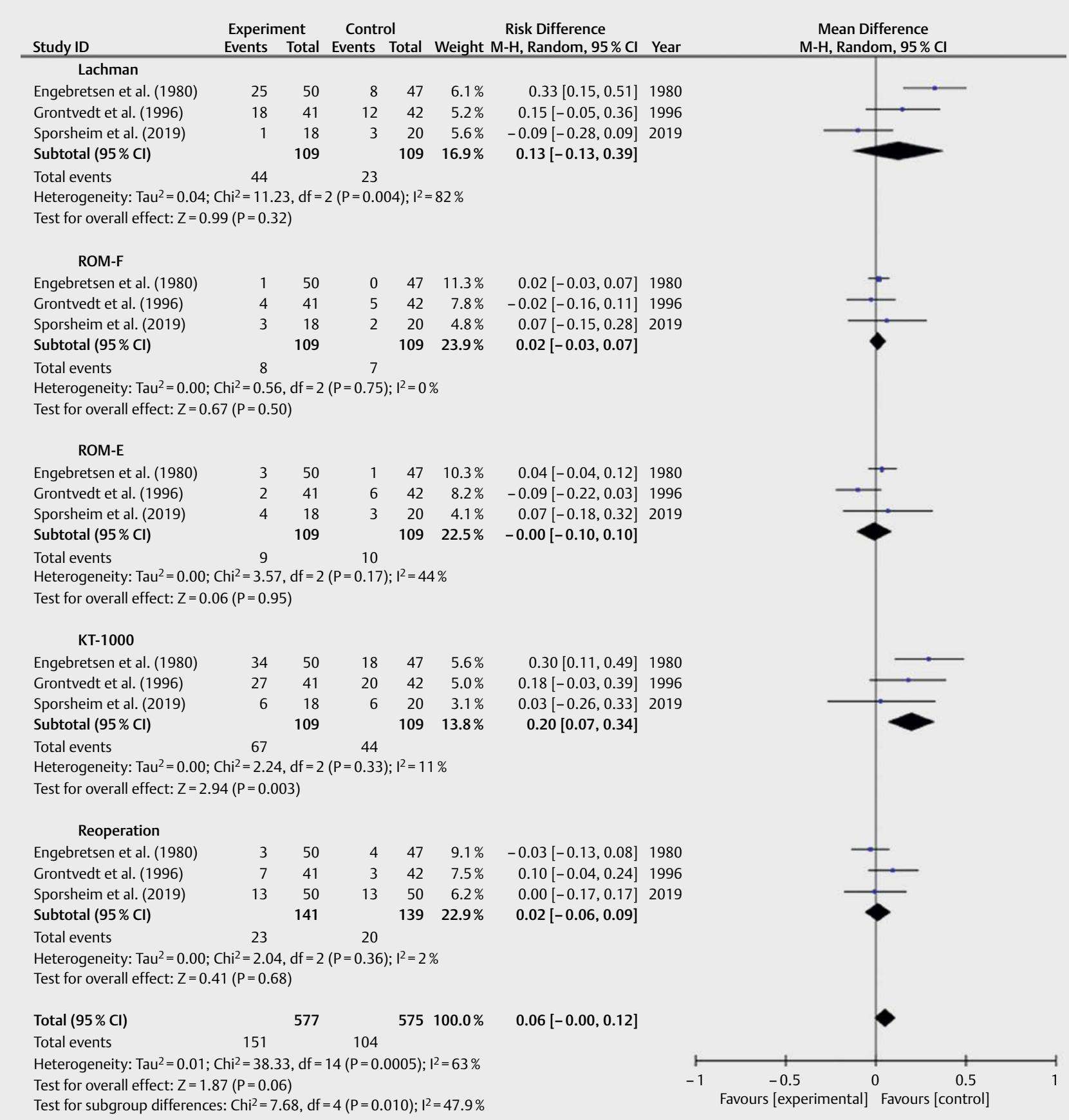

- Fig. 10 Difference in the categorical variable results for ACL repair and the subgroup analysis. $\mathrm{Cl}$, confidence interval; M-H, Mantel-Haenszel. The solid squares indicate the mean difference and are proportional to the weights used in the meta-analysis. The solid vertical line indicates no effect. The horizontal lines represent the $95 \% \mathrm{Cl}$. The diamond indicates the weighted mean difference, and the lateral tips of the diamond indicate the associated $95 \% \mathrm{Cl}$.

\section{Discussion}

This meta-analysis evaluates the difference in surgical efficacy between ACL repair and ACLR. The main finding is that there was no significant difference in clinical results between $A C L$ repair and ACLR group, including IKDC, range of motion (ROM), Lachman test, laxity difference, reoperation rate and muscle strength. No matter whether LAD was used or not, there was no obvious difference in the postoperative curative effect of ACL repair. Except for Tegner and Lysholm scores, which showed that the ACLR group had better recovery of postoperative motor function, the above results were promising. At the same time, subgroup analysis showed that the short-term follow-up results of arthroscopic ACL repair group were indeed better than those of open ACL repair group and generally comparable to those of the ACLR group. 
- Table 2 Postoperative Rehabilitation Protocols

\begin{tabular}{|c|c|c|c|c|c|c|c|c|c|}
\hline \multirow{2}{*}{$\begin{array}{l}\text { Included } \\
\text { studies }\end{array}$} & \multirow[t]{2}{*}{ Cast immobilization } & \multirow{2}{*}{$\begin{array}{l}\text { brace } \\
\text { immobiliza- } \\
\text { tion }\end{array}$} & \multicolumn{2}{|c|}{ Weight bearing } & \multirow[t]{2}{*}{ Knee ROM } & \multicolumn{4}{|c|}{ Guided physiotherapy } \\
\hline & & & Partial & full & & $\begin{array}{l}\text { Closed } \\
\text { Chain }\end{array}$ & $\begin{array}{l}\text { Propriocep- } \\
\text { tive exercis- } \\
\text { es }\end{array}$ & running & $\begin{array}{l}\text { return } \\
\text { to } \\
\text { sports }\end{array}$ \\
\hline \multirow[t]{2}{*}{$\begin{array}{l}\text { Engebretsen } \\
\text { et al. (1990) } \\
{[24]}\end{array}$} & $2 w k$ & $\begin{array}{l}30^{\circ} \text { of flexion } \\
\text { for } 6 \mathrm{wk}\end{array}$ & After 8 wk & & $\begin{array}{l}30-60^{\circ} \text { at } \\
3-4 w k\end{array}$ & After 12 wk & & NA & $12 \mathrm{mo}$ \\
\hline & & & & & $\begin{array}{l}30-90^{\circ} \text { at } \\
5-8 w k\end{array}$ & & & & \\
\hline \multirow{2}{*}{$\begin{array}{l}\text { Grontvedt et } \\
\text { al. (1996) } \\
{[25]} \\
\end{array}$} & $2 \mathrm{wk}$ & $\begin{array}{l}30^{\circ} \text { of flexion } \\
\text { for } 6 \mathrm{wk}\end{array}$ & After 8 wk & & $\begin{array}{l}30-60^{\circ} \text { at } \\
3-4 w k\end{array}$ & After $12 \mathrm{wk}$ & & NA & $12 \mathrm{mo}$ \\
\hline & & & & & $\begin{array}{l}30-90^{\circ} \text { at } \\
5-8 w k\end{array}$ & & & & \\
\hline $\begin{array}{l}\text { Sporsheim } \\
\text { et al. (2019) } \\
{[26]}\end{array}$ & $2 \mathrm{wk}$ & $\begin{array}{l}30^{\circ} \text { of flexion } \\
\text { for } 6 \mathrm{wk}\end{array}$ & After 8 wk & & NA & NA & & NA & $12 \mathrm{mo}$ \\
\hline $\begin{array}{l}\text { Schliemann } \\
\text { et al. (2018) } \\
{[17]}\end{array}$ & $4 d$ & NA & After $2 \mathrm{wk}$ & & $\begin{array}{l}\text { Unrestrict- } \\
\text { ed after } 2 \\
\text { wk }\end{array}$ & $2 w k-3 w k$ & $3 w k-6 w k$ & After $6 w k$ & $5 \mathrm{mo}$ \\
\hline $\begin{array}{l}\text { Hoogeslag } \\
\text { et al. (2019) } \\
{[20]}\end{array}$ & $\begin{array}{l}\text { DIS: A long-leg cast for } 5 \mathrm{~d} \text {; } \\
\text { ACLR: immediate Unrestrict- } \\
\text { ed; then received a } \\
\text { near-identical, structured, } \\
\text { criteria-based rehabilitation } \\
\text { protocol }\end{array}$ & & & & & & & & \\
\hline \multirow[t]{2}{*}{$\begin{array}{l}\text { Murray et al. } \\
(2020) \text { [18] }\end{array}$} & NA & $\begin{array}{l}\text { locking for } 6 \\
\text { wk }^{*}\end{array}$ & $4 \mathrm{wk}$ & $\begin{array}{l}\text { After } \\
4 \mathrm{wk}\end{array}$ & $\begin{array}{l}0-50^{\circ} \text { at } \\
2 w k\end{array}$ & $\begin{array}{l}\text { physical } \\
\text { therapy } \\
\text { protocol } \\
\text { from MOON }\end{array}$ & & & NA \\
\hline & & $\begin{array}{l}\text { movable at } \\
6-12 \mathrm{wk}^{*}\end{array}$ & & & $\begin{array}{l}0-90^{\circ} \text { at } \\
2-6 \text { wk }\end{array}$ & & & & \\
\hline $\begin{array}{l}\text { Sters et al. } \\
\text { (2020) [19] }\end{array}$ & NA & $5 d$ & $\begin{array}{l}20 \mathrm{~kg} \text { at } \\
0-2 \mathrm{wk}\end{array}$ & $\begin{array}{l}\text { After } \\
2 \mathrm{wk}\end{array}$ & $\begin{array}{l}\text { Unrestrict- } \\
\text { ed after } 5 d\end{array}$ & $5 \mathrm{~d}$ to $4 \mathrm{wk}$ & After 4 wk & NA & $6 \mathrm{mo}$ \\
\hline $\begin{array}{l}\text { The rehabilita } \\
\text { not applicable } \\
\text { Multicenter O } \\
12 \text { weeks. }\end{array}$ & $\begin{array}{l}\text { ion protocols depicted in the } t \\
\text { d, day; wk, week; mo, month } \\
\text { thopaedics Outcomes Networ }\end{array}$ & $\begin{array}{l}\text { le are for the } p \\
\text { CLR, anterior } \mathrm{c} \\
\text { Kg, kilograms. }\end{array}$ & $\begin{array}{l}\text { tients who } \\
\text { uciate ligam } \\
{ }^{*} \text { Use of lock }\end{array}$ & $\begin{array}{l}\text { derwe } \\
\text { t recor } \\
\text { hinge }\end{array}$ & $\begin{array}{l}\text { primary ACL } \\
\text { ruction; DIS, } \\
\text { eee brace for }\end{array}$ & $\begin{array}{l}\text { pair or recon } \\
\text { ynamic intral } \\
\text { weeks, then }\end{array}$ & $\begin{array}{l}\text { uction.; ROM } \\
\text { mentary stab } \\
\text { e of functiona }\end{array}$ & $\begin{array}{l}\text { nge of mot } \\
\text { ation; } \mathrm{MOC} \\
\mathrm{CL} \text { brace } \mathrm{fo}\end{array}$ & to \\
\hline
\end{tabular}

Open primary repair of ACL injury was gradually abandoned many years ago, Part of the reason is that the follow-up results for patients were not satisfactory, which showed that pain, joint swelling, instability, persistent symptoms were not relieved, and the incidence of reoperation rate was high. The research reported by Feagin showed that although the early curative effect was satisfactory, in the following 5 years of follow-up, only 5 of the initial 64 patients had symptoms relieved. $91 \%$ of the patients had unstable conditions, and 15 patients need reoperation [4]. Although other literatures had reported that the success rate could reach $75 \%$ in 6 years, there were still a large number of literatures confirming the above unsatisfactory results. This study included three research on open $A C L$ repair. After integrating the data of open $A C L$ repair with or without $L A D$, we found that in the short-term follow-up (25year), the results showed that the failure rate was higher in the open $A C L$ repair group, the instability gradually increased with time and stabilized after 5 years, with lower activity and function levels.
The BPTB group was indeed much better than the open $A C L$ repair group. This may be one of the reasons why meta-analysis results showed that Tegner and Lysholm scores of open ACL repair group were lower than those of ACLR group. This was also consistent with the results of the above historical literature. Although the 5-year follow-up results showed that there was no significant difference in knee ROM, and the reoperation rate of open $A C L$ repair was basically the same as that of BPTB group, LARS and other scholars still suggested that non-enhanced $A C L$ repair should not be performed again. On the other hand, the results of 30-year follow-up of ACLrepair patients by Anne showed that with the increase of follow-up time, the stability of knee joint in each group was increasing, and few patients still had substantial relaxation. The unstable patients who appeared during the follow-up period of 5-16 years also obtained more stable year by year. Meta-analysis also showed that there was no significant difference in knee stability and ROM among the groups. The average age of 30-year follow-up patients reported 
by ANNE was 60 years old, which was another reason for the lower Tegner and Lysholm scores of the two groups, as the activity level of the elderly is usually lower. In addition, the development of osteoarthritis (OA) was also a factor to be considered for the recovery of knee stability.

Another point to note is that the reoperation rate of $\mathrm{ACL}$ repair group after 30-year follow-up reported by ANNE was higher than that of ACLR group. This was not appeared during short-term follow-up. The main defect of $A C L$ repair is in the difficulty of healing. The repair of $A C L$ is relatively difficult in the synovial environment. After the fibrin plug in the synovial space is destroyed by fibrinolytic enzyme, fibroblasts will cover the surface of ACL, and the early healing will be prevented [32]. This undoubtedly makes $A C L$ repair more difficult. Cabaud er al. had confirmed that early ACL repair would always fail completely, and the use of LAD has better results [33]. LAD was first invented by Kennedy to enhance the repair or reconstruction of ACL injuries [34]. Schabus first applied LAD and reported good clinical results [35]. Engebretsen et al. had confirmed in cadaver research that LAD can provide about $75 \%$ of the extension and flexion activity load of ACL tissue in the early stage, which protects the early repair of $A C L$ from being damaged until the tissue fully grows and the repair is completed [36]. This is consistent with our meta-analysis results. In short-term follow-up (2-5 years), the clinical outcomes, stability and activity function in LAD group were indeed better than those without LAD. But the protective function of LAD can only last for about 1 year. So, with the increase of follow-up time, this advantage gradually disappeared. As mentioned before, the reoperation rate of $A C L$ repair was significantly higher than that of BPTB group, which was consistent with the similar results reported by some scholars: supporting the disadvantage of LAD compared with autologous BPTB or hamstring tendon transplantation $[37,38]$. This is not only related to the degeneration and aging of tissues after $A C L$ repair, but also related to the wear of $L A D$ and the mechanical deterioration of synthetic material fragments [39].

Therefore, through analysis, it was not difficult to figure out why open $A C L$ repair was abandoned by surgeons at that time: the invasive and rough technology of open arthrotomy, long time fixation and high revision rate were the important reasons. Although some scholars put forward the view that the disappointing effect of open ACL repair was largely due to the wrong choice of patients. After reviewing historical literature, Van et al. found that the location of $A C L$ rupture seems to play an important role in the prognosis of open ACL repair [40]. Some studies had confirmed that selective open $A C L$ repair for proximal ACL rupture had a very good prognosis and would not deteriorate with time, while the prognosis for middle ACL rupture was disappointing [41]. Unfortunately, there was no more high-quality research to explore this issue. The RCTs we included also did not statistically analyze the location of $\mathrm{ACL}$ rupture. Therefore, we could not make more judgments.

With the rapid development of arthroscopy and arthroscopic surgery in recent years, there is a renewed interest in the primary repair of $A C L$ injury. Especially, the research on the proprioceptive effect of ACL tissue is deepening. Some studies had shown that preserving the injured stump of ACL can improve the mechanical stability of knee joint after operation and allow earlier and more active rehabilitation exercise, which is very important for athletes with ACL injury [1]. Therefore, the main concern of modern joint surgeons is how to keep this function in patients with ACL injury, especially athletes. The intervention measures of arthroscopic $A C L$ repair included in this study were DIS and BEAR. The above two approaches can effectively preserve their own ACL stumps while enhancing the biomechanical properties of repaired ACL through augmentation devices [42-45]. Biery et al. reported the 2-year followup results showed that DIS patients returned to work and exercise earlier than the traditional ACLR, while there was no difference in treatment cost, revision rate and clinical outcomes [46]. Eggli et al. followed up DIS patients for 5 years and found that the postoperative success rate could reach $80 \%$ [42]. The results of the above historical literature were consistent with this study. Through systematic analysis, we found that patients in arthroscopic ACL repair group, including DIS and BEAR group, not only had no significant difference in clinical score, physical examination, reoperation rate and postoperative muscle strength recovery from ACLR group, but also achieved better results in IKDC score during short-term followup. By subgroup analysis, it was not difficult to find that compared with open ACL repair, arthroscopic ACL repair did show greater advantages: higher postoperative activity function level and less reoperation rate.

Another great advantage of arthroscopic ACL repair is that it can resume activity earlier. We noticed that the rehabilitation program in the early decades included long-leg cast fixation for at least 5-6 weeks, and then partial weight bearing was allowed after 8 weeks. As we all know, long-time knee joint fixation is one of the main causes of knee joint pain, decreased mobility and functional loss [47]. However, the concept of early rapid rehabilitation gradually emerged around 1990 [48]. Therefore, the lagging postoperative rehabilitation program was also one of the important factors for the poor activity function outcome in patients after open $A C L$ repair. Genelin et al. had confirmed that the use of continuous passive movement machines in the early postoperative period of patients with primary ACL repair combined with braces providing limited knee joint movement could further improve the postoperative effect [49]. The rehabilitation programs of the arthroscopic ACL repair studies we included basically did not use the continuous fixation after operation, which was used by open $A C L$ repair, instead of the early partial or completely unlimited joint movement and the advance of weight-bearing time. The time for returning to sports reported by several included studies was basically about 5-6 months. This undoubtedly played an important role in the recovery of activity function after operation. Unfortunately, we had not found a study to evaluate the difference in activity recovery speed between $A C L$ repair and ACLR group, which needs further study.

\section{Limitations}

There are some limitations in this study. No RCT study had discussed and analyzed the location of ACL injury. Considering that the $A C L$ repair effect of patients with proximal $A C L$ rupture is better, an in-depth study is necessary for patient selection and refinement of surgical indications. Secondly, because only RCT research is included, the number of related literatures, the total number of patients, and the included analysis indicators were few, which might have some impacts on the combined results. Besides, Except 
for a 30-year follow-up literature, the follow-up time of other literatures was short, which might not better judge the long-term effect of ACL repair patients. In addition, all included studies did not report the follow-up results of postoperative complications and clinical symptoms of patients. And there was no clear comparative evaluation on the recovery speed of early activity.

\section{Conclusion}

This systematic review using meta-analysis found that at shortterm follow-up, the postoperative clinical efficacy of arthroscopic $A C L$ repair was comparable to $A C L R$, but the prognosis of open $A C L$ repair was relatively unsatisfactory. Therefore, we can make the conclusion that the arthroscopic ACL repair technique is an optional and promising surgical method to treat ACL injury. Of course, we still need more prospective controlled studies with long follow-up time to confirm our conclusions.

\section{Conflict of Interest}

The authors declare that they have no conflict of interest.

\section{References}

[1] Diermeier T, Rothrauff BB, Engebretsen $L$ et al. Treatment after anterior cruciate ligament injury: Panther Symposium ACL Treatment Consensus Group. Knee Surg Sports Traumatol Arthrosc 2020; 28: 2390-2402

[2] Robson AW. VI. Ruptured crucial ligaments and their repair by operation. Ann Surg 1903; 37: 716-718

[3] Cabaud HE, Feagin JA, Rodkey WG. Acute anterior cruciate ligament injury and augmented repair. Experimental studies. Am J Sports Med 1980; 8: 395-401

[4] Feagin JA, Abbott HG, Rokous JR. Isolated tear of the anterior cruciate ligament: 5-year follow-up study. Am J Sports Med 1976; 4: 95-100

[5] Spencer EE, Chissell HR, Spang JT et al. Behavior of sutures used in anterior cruciate ligament reconstructive surgery. Knee Surg Sports Traumatol Arthrosc 1996; 4: 84-88

[6] Cabaud HE, Rodkey WG, Feagin JA. Experimental studies of acute anterior cruciate ligament injury and repair. Am J Sports Med 1979; 7 : $18-22$

[7] Samuelsen BT, Webster KE, Johnson NR et al. Hamstring autograft versus patellar tendon autograft for $\mathrm{ACL}$ reconstruction: is there a difference in graft failure rate? a meta-analysis of 47,613 Patients. Clin Orthop Relat Res 2017; 475: 2469-2471

[8] Proffen BL, Sieker JT et al. Bio-enhanced repair of the anterior cruciate ligament. Arthroscopy 2015; 31: 990-997

[9] Seijas R, Ares O, Cuscó X et al. Partial anterior cruciate ligament tears treated with intraligamentary plasma rich in growth factors. World J Orthop 2014; 5: 373-378

[10] Fayard JM, Sonnery-Cottet B, Vrgoc G et al. Incidence and risk factors for a partial anterior cruciate ligament tear progressing to a complete tear after nonoperative treatment in patients younger than 30 years. Orthop J Sports Med 2019; 7: 2325967119856624

[11] Sonnery-Cottet B, Bazille C et al. Histological features of the ACL remnant in partial tears. Knee 2014; 21: 1009-1013
[12] Sonnery-Cottet B, Zayni R, Conteduca J et al. Posterolateral bundle reconstruction with anteromedial bundle remnant preservation in $A C L$ tears: clinical and MRI evaluation of 39 patients with 24-month follow-up. Orthop J Sports Med 2013; 1: 2325967113501624

[13] Murray MM, Fleming BC. Biology of anterior cruciate ligament injury and repair: kappa delta ann doner vaughn award paper 2013. J Orthop Res 2013; 31: 1501-1506

[14] Takazawa Y, Ikeda $\mathrm{H}$, Kawasaki T et al. ACL reconstruction preserving the $A C L$ remnant achieves good clinical outcomes and can reduce subsequent graft rupture. Orthop J Sports Med 2013; 1 : 2325967113505076. doi: 10.1177/2325967113505076

[15] Kraeutler M], Bravman JT, Mccarty EC. Bone-patellar tendon-bone autograft versus allograft in outcomes of anterior cruciate ligament reconstruction: a meta-analysis of 5182 patients. Am J Sports Med 2013; 41: 2439-2448

[16] Van D, Difelice GS. Range of motion and complications following primary repair versus reconstruction of the anterior cruciate ligament. Knee 2017; 24: 798-807

[17] Schliemann B, Glasbrenner ], Rosenbaum D et al. Changes in gait pattern and early functional results after $A C L$ repair are comparable to those of ACL reconstruction. Knee Surg Sports Traumatol Arthrosc 2018; 26: 374-380

[18] Murray MM, Fleming BC, Badger G] et al. Bridge-enhanced anterior cruciate ligament repair is not inferior to autograft anterior cruciate ligament reconstruction at 2 years: results of a prospective randomized clinical trial. Am J Sports Med 2020; 48: 1305-1315

[19] Sters CK, Glasbrenner J, Spickermann L et al. Repair with dynamic intraligamentary stabilization versus primary reconstruction of acute anterior cruciate ligament tears: 2-year results from a prospective randomized study. Am J Sports Med 2020; 48: 1108-1116

[20] Hoogeslag R, Brouwer RW, Boer BC et al. Acute anterior cruciate ligament rupture: repair or reconstruction? two-year results of a randomized controlled clinical trial. Am J Sports Med 2019; 47: 567-577

[21] Rocco P, Guglielmo T, Giuseppe P et al. Arthroscopic primary repair of the anterior cruciate ligament in adults: a systematic review. $\mathrm{Br}$ Med Bull 2019; 1: 29-42

[22] Van der List JP, Vermeijden HD, Sierevelt IN et al. Arthroscopic primary repair of proximal anterior cruciate ligament tears seems safe but higher level of evidence is needed: a systematic review and metaanalysis of recent literature. Knee Surg Sports Traumatol Arthrosc 2020; 28: 1946-1957

[23] Kandhari V, Ouanezar H, Praz C et al. Clinical outcomes of arthroscopic primary anterior cruciate ligament repair: a systematic review from the scientific anterior cruciate ligament network international study group. Arthroscopy 2020; 36: 594-612

[24] Engebretsen L, Benum P, Fasting O et al. A prospective, randomized study of three surgical techniques for treatment of acute ruptures of the anterior cruciate ligament. Am J Sports Med 1990; 18: 585-590

[25] Grontvedt T, Engebretsen L, Benum P et al. A prospective, randomized study of three operations for acute rupture of the anterior cruciate ligament. Five-year follow-up of one hundred and thirty-one patients. J Bone Joint Surg Am 1996; 78: 159-168

[26] Sporsheim AN, Gifstad T, Lundemo TO et al. Autologous BPTB ACL reconstruction results in lower failure rates than $A C L$ repair with and without synthetic augmentation at 30 years of follow-up. J Bone Joint Surg Am 2019; 101: 2074-2081

[27] Drogset JO. A sixteen-year follow-up of three operative techniques for the treatment of acute ruptures of the anterior cruciate ligament. J Bone Joint Surg Am 2006; 88: 944-952

[28] Palmer I. On the injuries to the ligaments of the knee joint: a clinical study. 1938. Clin Orthop Relat Res 2007; 454: 17-22 
[29] Kösters C, Herbort M, Schliemann B et al. Dynamische intraligamentäre Stabilisierung des vorderen Kreuzbandes. Unfallchirurg 2015; 118: 364-371

[30] Eggli S, Kohlhof H, Zumstein M et al. Dynamic intraligamentary stabilization: novel technique for preserving the ruptured $\mathrm{ACL}$. Knee Surg Sports Traumatol Arthrosc 2015; 23: 1215-1221

[31] Murray MM, Kiapour AM, Kalish LA et al. Predictors of healing ligament size and magnetic resonance signal intensity at 6 months after bridge-enhanced anterior cruciate ligament repair. Am J Sports Med 2019; 47: 1361-1369

[32] Andersen RB, Gormsen J. Fibrin dissolution in synovial fluid. Scand ] Rheumatol 1987; 16: 319-333

[33] Ca Baud HE, Feagin JA, Rodkey WG. Acute anterior cruciate ligament injury and repair reinforced with a biodegradable intraarticular ligament. Experimental studies. Am J Sports Med 1982; 10: 259-265

[34] Kennedy J, Roth J, Mendenhall $H$ et al. Intraarticular replacement in the anterior cruciate ligament-deficient knee. Am J Sports Med 1980; 8: 1-8

[35] Schabus R. Die Bedeutung der Augmentation für die Rekonstruktion des vorderen Kreuzbandes. Hollinek, 1988

[36] Engebretsen L, Lew WD, Lewis JL et al. Knee joint motion and ligament force in nonaugmented and augmented primary repairs of anterior cruciate ligament ruptures. Am J Sports Med 1989; 17: 706-707. doi: $10.1177 / 036354658901700542$

[37] Savarese A, Lunghi E, Budassi P et al. Remarks on the complications following $\mathrm{ACL}$ reconstruction using synthetic ligaments. Ital J Orthop Traumatol 1993; 19: 79-86

[38] Gifstad T, Sole A, Strand T et al. Long-term follow-up of patellar tendon grafts or hamstring tendon grafts in endoscopic $\mathrm{ACL}$ reconstructions. Knee Surg Sports Traumatol Arthrosc 2013; 21: 576-583

[39] Olson EJ, Kang JD, Fu FH et al. The biochemical and histological effects of artificial ligament wear particles: In vitro and in vivo studies. Am J Sports Med 1988; 16: 558-570
[40] Van der List JP, DiFelice GS. Role of tear location on outcomes of open primary repair of the anterior cruciate ligament: a systematic review of historical studies. Knee 2017; 24: 898-908

[41] Van der List JP, DiFelice GS. Primary repair of the anterior cruciate ligament: a paradigm shift. Surgeon 2017; 15: 161-168

[42] Eggli S, Röder C, Perler G et al. Five-year results of the first ten ACL patients treated with dynamic intraligamentary stabilisation. BMC Musculoskelet Disord 2016; 17: 105. doi: 10.1186/s12891-016-0961-7

[43] Evangelopoulos DS, Kohl S, Schwienbacher $S$ et al. Collagen application reduces complication rates of midsubstance ACL tears treated with dynamic intraligamentary stabilization. Knee Surg Sports Traumatol Arthrosc 2017; 25: 2414-2419

[44] Kohl S, Evangelopoulos DS, Ahmad SS et al. A novel technique, dynamic intraligamentary stabilization creates optimal conditions for primary ACL healing: a preliminary biomechanical study. Knee 2014; 21: $477-480$

[45] Murray MM, Kalish LA, Fleming BC et al. Bridge-enhanced anterior cruciate ligament repair: two-year results of a first-in-human study. Orthop J Sports Med 2019; 7: 2325967118824356. doi: 10.1177/ 2325967118824356

[46] Murray MM, Flutie BM, Kalish LA et al. The bridge-enhanced anterior cruciate ligament repair (BEAR) procedure: an early feasibility cohort study. Orthop J Sports Med 2016; 4: 2325967116672176. doi: 10. $1177 / 2325967116672176$

[47] Millett PJ, Wickiewicz TL, Warren RF. Motion loss after ligament injuries to the knee. Part I: causes. Am J Sports Med 2001; 29: 664-675

[48] Anderson AF, Lipscomb AB. Analysis of rehabilitation techniques after anterior cruciate reconstruction. Am J Sports Med 1989; 17: 154-160

[49] Genelin F, Trost A, Primavesi C et al. Late results following proximal reinsertion of isolated ruptured ACL ligaments. Knee Surg Sports Traumatol Arthrosc 1993; 1: 17-19 